\title{
Barriers to innovation in online pedagogy
}

\section{Christie \& R. Garrote Jurado}

To cite this article: M. Christie \& R. Garrote Jurado (2009) Barriers to innovation in online pedagogy, European Journal of Engineering Education, 34:3, 273-279, DOI: 10.1080/03043790903038841

To link to this article: http://dx.doi.org/10.1080/03043790903038841

央 Published online: 16 Jun 2009.

Submit your article to this journal $\pi$

Џ Article views: 177

Q View related articles $\asymp$

4 Citing articles: 8 View citing articles 준 


\title{
Barriers to innovation in online pedagogy
}

\author{
M. Christie ${ }^{\mathrm{a}}$ and R. Garrote Jurado ${ }^{\mathrm{b}}$ \\ ${ }^{a}$ CKK, ITU, Chalmers, Göteborg, Sweden; ${ }^{b}$ Engineering Department, University College of Borås, Borås, \\ Sweden
}

(Received 20 October 2008; final version received 8 May 2009)

\begin{abstract}
In this article, the authors report on a study that was carried out at the University College of Borås. Teachers using an online learning platform (WebCT) were surveyed to see to what extent they made use of the various features available to them on the learning platform. The extent to which teachers employed all the features was low. The article provides comparative details about the use of the various features (chat, discussion forums, assessment etc) and analyses reasons for their underutilisation. This case study is used to make more general points about pedagogy of online learning and discusses the need for greater cooperation between all the stakeholders involved in putting courses online. It can be counter productive for a university to simply impose a learning management system upon its teaching staff and decree that they put their courses online. If a university is concerned with quality and innovation in the education it offers its students, then a great deal of groundwork needs to be done if teachers and students are going to get the most out of a move to blended or online learning. This article offers a number of recommendations for ensuring that teachers embrace rather than resist a move to innovative and quality assured online education.
\end{abstract}

Keywords: online learning; pedagogical use of learning management systems; engineering education

\section{Introduction}

This article builds on research that has been published previously by Garrote Jurado and Tomas Pettersson (2007) and uses data from that research to argue more generally about the barriers that face engineering educators who want to, or are required to, put their courses online. We not only look at the barriers they face but also how they might overcome them. We argue that learning management systems (LMS) are a force for innovation in engineering education. Understanding why teachers underutilise this type of computer software will help all stakeholders to make better use of it. University leaders, administrators, teachers, researchers and students all have a stake in seeing that they get value from an investment in an expensive computer programme designed to improve teaching and learning.

Different countries tend to use different terms to describe LMS, which we define as a computer program that integrates functions for teaching, learning, evaluation and administration of educational courses. In Sweden, terms such as Learning Platforms and Virtual Learning Environments are not uncommon (Björk 2004). In this article, we will refer both to LMS and learning

*Corresponding author. Email: mich@chalmers.se

ISSN 0304-3797 print/ISSN 1469-5898 online

(C) 2009 SEFI

DOI: $10.1080 / 03043790903038841$

http://www.informaworld.com 
platforms, since the latter term has the advantage of emphasising the pedagogical purpose of such programs. Today there are a number of commercial programs. BlackBoard and WebCT are two of the largest but it is not always easy to keep up with the amalgamations and buy outs that are part of internet business today. Since the national language used in an LMS can be an important selling point, entrepreneurs in non-English speaking countries often develop their own LMS. Norway, for example, has an LMS called Fronter and Sweden one called PingPong.

Although some universities in the late 1990s and at the start of this century developed their own LMS, it is rare, today, for universities to risk such an investment in time, money and staff. Two interesting examples of a custom-built LMS are the online learning and teaching (OLT) system built by Queensland University of Technology (QUT) and an LMS that was commissioned from Java by the UKeU, a short-lived experiment in the creation of a 'virtual university' where all courses were to be delivered online. In Australia, where distance education is well established, it was natural that QUT, one of Australia's biggest distance learning providers should try to develop its OLT system when there were not so many commercial systems available. The OLT system was used from the late 1990s until recently when costs became prohibitive and a commercial system was brought ${ }^{1}$. The UKeU system was well advanced when the British government abandoned its virtual university project because of high costs and a failure to attract sufficient students (Christie 2007). Today Australian universities, in the main, have bought commercial LMS, renamed them and adapted them to their own purposes. The same can be said for most universities in the so called 'developed' countries. A government investigation sponsored by Sweden's agency for networking and cooperation in higher education sought to influence the purchase of a common system by inviting LMS companies to detail the advantages of their particular systems. Today the Swedish LMS called PingPong is in use in a number of major universities in Sweden.

\section{The case study}

Lecturers at the School of Engineering at the University College of Borås have had the opportunity to use WebCT since 1999. For this investigation 22 lecturers were interviewed in 2006 about their use of this LMS in courses that were run during the first 10 months of that year. The method we used combined literature review and systematic observations to obtain quantitative data (Dutton et al. 2004; Bongalos et al. 2006). To minimise and if possible eliminate variation in the results, a scheme of observations was organised (Denscombe 2006). We did this by asking teachers about six of the most important tools that one can use in WebCT, namely: Pages, URL, Course Content Tools, Communications Tools, Evaluation and Activity Tools and Student Tools. Since one of the investigators was also the system administrator, it was possible to not only interview the teachers about their use but also go in and look at the range of tools that were being used in each course. The observations were booked in a spreadsheet. The spreadsheet had a row for each course as well as columns that corresponded to every tool in the LMS. We also had some columns relating to administration where we could note the current status of the course and, if it had been completed, whether or not the results had been placed in Ladok, the student administrative system. Furthermore, a column called 'multimedia' was inserted to report on the extent to which lecturers uploaded images, animations or videos for use in their courses (Figure 1).

Every tool in the LMS that was found in a course during the investigation was filed in our observation scheme either as 'existing' or 'in use'. 'Existing' meant that the tool was inserted in the course. A teacher or system administrator has the choice of inserting a range of available tools once a course room or event is activated. In some cases, the teacher inserted the tool in the course and tested it without later using it in an active way in the education process. A teacher can decide whether a tool should be seen by the students or not. If a tool was booked as 'in use' it meant 


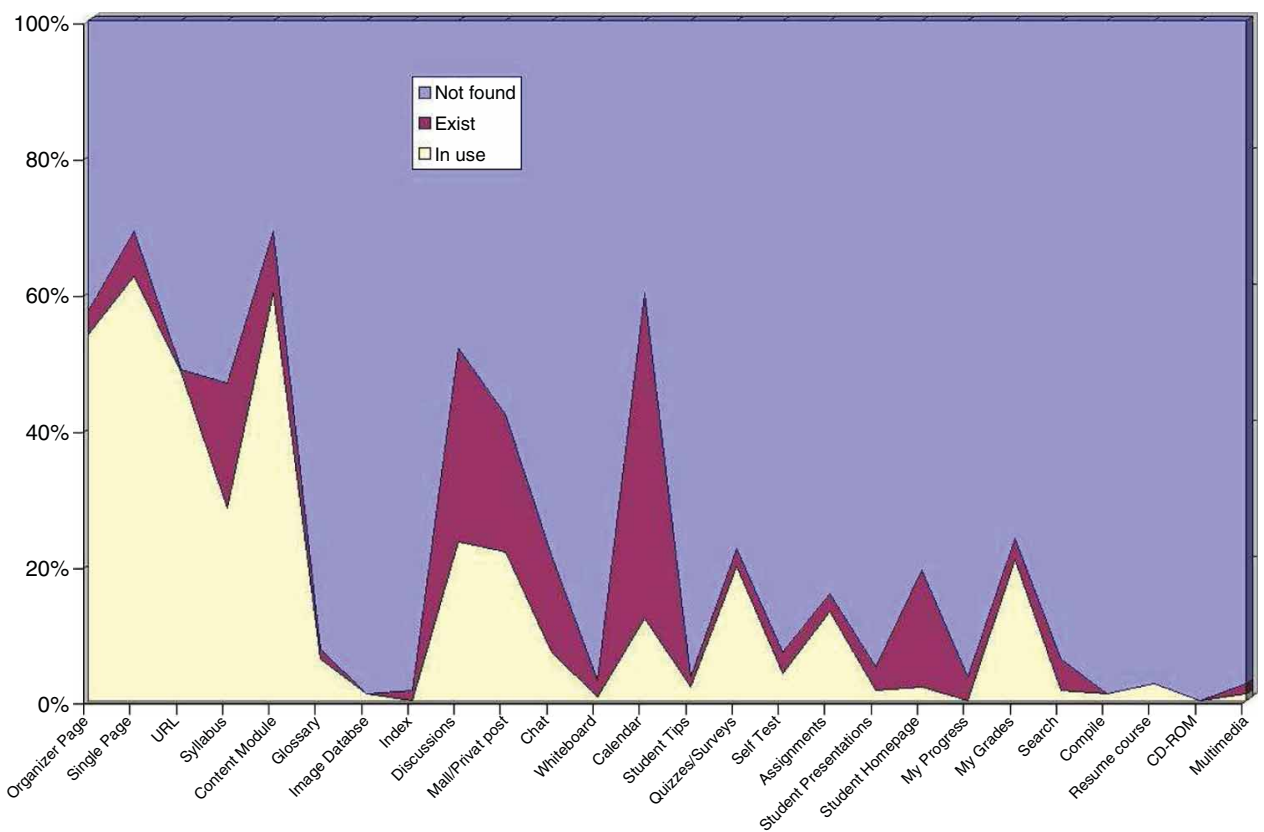

Figure 1. A summary of the extent to which WebCT tools exist, are in use or are not found in courses.

that it had been used in an active way in the course. The cells in our spreadsheet that were left blank showed that the tool was not to be found in the course. After analysing the results of our spreadsheet, the lecturers were divided up into three categories in terms of how much they had used the tools in WebCT. Their responses to questions 1-6, which related to the use of the most common tools, were also employed in creating these categories. The categories of teachers were 'least experienced', 'intermediate' and 'most experienced'. The most experienced group, seven people, were lecturers who had used at least five of the six kinds of tools; the intermediate group, eight people, had used three to four kinds of tools and the last group, seven people, had used at most two kinds of tools. In our investigation model, we were concerned with both reliability and validity. Reliability means the measurement is repeatable and consistent no matter if one or more observers collect data. A high level of reliability is reached when systematic observations are carried out using the same data collection mechanism. We felt that collecting a complete set of data would give us the highest possible reliability, even though the sample group was too small to include correlations. For those who are interested, the correlation coefficient only exceeded 0.6 in three cases. Questions 9 and 20 have a correlation coefficient of 0.74 ; questions 15 and 21 had -0.68 and questions 20 and 22 had a correlation coefficient of -0.63 .

We used the teacher categories when charting the responses to questions 7-23, which focus more on general attitudes to LMS than on the specific use of tools within WebCT (Figure 2). These questions were in the form of statements to which the teachers could respond using a scale of $1-5$, where 1 equalled 'totally agree' and 5 equalled 'do not agree at all'. The complete set of statements was as follows:

(7) An LMS will be used by most lecturers within a few years.

(8) An LMS can increase study performance.

(9) An LMS can facilitate the lecturer's work considerably.

(10) You will use most parts of an LMS within the next few years.

(11) You want more education and support to be able to use all components of an LMS. 


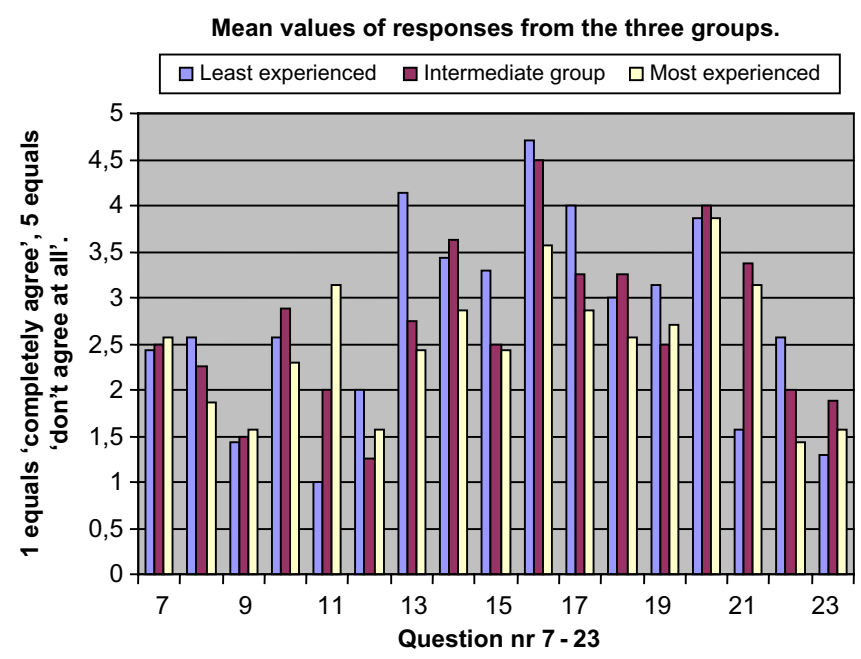

Figure 2. Responses to questions 7-23 divided according to category of the teacher.

(12) An LMS can be a great help in the courses you teach.

(13) You had a sufficient introduction to start using WebCT.

(14) There is a good help to get if there is a problem with WebCT.

(15) If you have questions about the LMS you can always get help.

(16) There is a good discussion going on among the lecturers on how to use the LMS.

(17) Within the institution the lecturers are encouraged to use the LMS.

(18) An LMS has a great impact on the teaching process.

(19) An LMS changes the planning and execution of courses.

(20) An LMS contributes to changes of course content.

(21) All lecturers will have to use an LMS in future.

(22) An LMS makes a big difference to students.

(23) All students will have to use an LMS in future.

\section{Analysis}

An analysis of the interviews and data mining relating to questions 1-6 showed that at the University College of Borås, teachers do not have the time or motivation to become experts in how to use an LMS. The most fundamental tools in the LMS (which we call content tools) enable teachers to create a course structure, publish document files, link to pages on the internet and allow students to download information. Our investigation showed that the content tools were used by about $60 \%$ of the courses in the survey. The tool that enabled teachers to create an image data base was used by only $6 \%$ of the teachers we interviewed. The use of an image database is important when a large number of pictures are needed to illustrate the content of the course. The use of communication tools was varied. Discussions, mail, chat and calendar have a frequent use that varies from $12 \%$ to $23 \%$. Whiteboard and student tips have a negligible use, whereas evaluation and activity tools such as quizzes/surveys and assignments were used in 13-20\% of the courses. The use of quizzes/surveys can be dependent on the type of course, the course plan and teachers' familiarity with using and trusting this tool. In our survey the use was limited. The use of the tool that allows students to hand in assignments was varied. The frequency with which it was used depended on the type of course, the plan of the course, the choice of examination in the course and the teachers' 
familiarity with the tool and his/her time and readiness to examine different types of assignments. In our survey, only $21 \%$ of the courses made regular use of tools that allowed students to submit assignments online and receive feedback about their results (Garrote Jurado 2006).

An analysis of the teachers' attitudes to statements 7-23 gives cause for both pessimism and optimism. It is fairly clear that most teachers think that the use of LMS will be expand greatly in the near future (Q7) and believe that an LMS can increase study performance (Q8) and facilitate teaching and learning (Q9). It is not unexpected that the more experienced teachers will increase their use of the tools in an LMS (Q10) since such usage builds on confidence. Nor is it surprising that it is the inexperienced group that wants more education and support (Q11). A cause for optimism is that all three categories feel strongly that an LMS can be a great help in the courses they teach. Questions 13-15 concerned the level of support teachers received, and it is clear there that the less experienced group wants a better introduction to the LMS even though that support appears to be fairly good. Statement 16 , and the teachers' response to it, is perhaps the one that is the most worrying. Teachers do not, in general, feel that there is a good discussion around LMS and its use in teaching and learning nor does the inexperienced group feel that within the institution the lecturers are encouraged to use LMS (Q17). Teachers are lukewarm when it comes to whether or not they think LMS have a great impact on the teaching process (Q18) and tend to sit on the fence in their view as to whether or not LMS changes the planning and execution of courses (Q19). All three groups disagree that LMS contributes to changes, of course, content $(\mathrm{Q} 20)$. The response to statement 21 is interesting because it is the inexperienced group that agrees most strongly that all lecturers at their school will have to use LMS in future (Q21). There is an increasing agreement with the last two statements, namely that an LMS makes a big difference to students (Q22) and that all students will have to use an LMS in the future (Q23). It is understandable that the inexperienced group are less sure about the positive difference that using an LMS can have for students (Q22).

\section{Conclusions}

A general conclusion is that online or blended learning courses probably do not have to use all of the tools in an LMS package. Depending on the content of the course itself, the course plan and whether it is an on-campus or a distance course, there can be different needs. Another point of view that can influence the use of various tools in online courses is how familiar students are with using LMS. Students who have got used to using an LMS from year one at the university college ought to be ready to use most of the possibilities in an LMS by their third year. For the further development of the use of LMS, it is important to offer continuous education, competence development and support in how to use an LMS. Our survey indicated that LMS is not being used to its full capacity at the School of Engineering at the University College of Borås. If we are to change this situation at Borås and other engineering schools, it is important to offer user support by experts on LMS. To simply transfer files on to an LMS without considering the design of the platform or the pedagogical use of its capacity is counter productive. All those concerned in the engineering education enterprise will be disappointed and dissatisfied if the opportunity to combine pedagogy and technology is missed. Researchers also have a key role to play, for more work needs to be done on how young peoples' learning styles have been affected by the out-ofschool use of the internet and other ICTs. It is important, for example, to find out how students acquire knowledge outside the formal learning environment in order to tailor online learning at universities to their needs and learning styles (Christie 2006).

The barriers to making use of technology to innovate and improve teaching and learning are not difficult to understand. Older teachers required time to adapt to the use of overhead transparencies even when they instinctively knew that it was pedagogically smarter to show a 
picture of complicated equipment during a lecture than to try to describe it in words. After some years, it was mainly the mathematicians that stuck to use of the black or white board (arguably for good educational reasons). It took time and a lot of trial and error before teachers made the next step to PowerPoint, a sophisticated system with an inbuilt pedagogy (large font size, limited space for text to avoid overload). Today, at a conference like this one, almost everybody uses PowerPoint. The problem is that it is not always used pedagogically or for the right reasons. A common reason for using PowerPoint in lectures today is as a prop. The slides act as a lesson plan and an insurance against 'forgetting one's lines' rather than as a means to use diagrams, illustrations, animation, videos and key points to enhance the explanation of difficult concepts or topics. As with LMS teachers use only a fraction of the technological possibilities that PowerPoint has to offer. Again the barriers to innovation are understandable. One must initially get help and invest a lot of time into making pedagogically worthwhile slides. This problem is exacerbated when teachers are required to, or chooses to, use LMS. The potential to present course material in innovative and pedagogical ways is enormous with an LMS but so is the learning curve required to realise such potential. A teacher who has a simple website where all his or her course material can be found, an email list that can be updated, an attachment facility that allows documents to be sent and so on, will have to be convinced that he or she needs an LMS. The initial investment in time must be seen to payoff in terms of greater efficiency as well as the potential for innovation and improvement. Students are less difficult to convince since they are more and more used to logging into sites and navigating around them. As we stated at the beginning of this article, it takes commitment on the part of all the stakeholders involved if barriers such as time, money, resistance to change and ignorance are to be overcome. Of all the stakeholders it is the university leadership that must show the way. Change can occur intermittently by dedicated individuals demonstrating the enormous potential that LMS has for distance and blended learning. But if more widespread change is to occur, it is the leaders at a university who must be prepared to commit time and money to see that if it happens. It takes time, money, organisation and enthusiasm to properly introduce administrators, teachers and researchers to LMS and help them to see, by trial and error that LMS, if used pedagogically, can lead to innovation and quality in higher education.

\section{Note}

1. Unpublished report of a study visit to QUT undertaken by M. Christie on 23 December 2003 as part of the C-SELT project, Chalmers. Copy available on request from the author.

\section{References}

Björk, U. 2004. Distributed problem based learning: studies of a pedagogical model in practice. Gothenburg: Acta Universitatis.

Bongalos, Y., Bulaon, D., de Celedonio, L., de Guzman, A., and Ogarte, C. 2006. University experiences in courseware development. British Journal of Educational Technology, 37, 695-704.

Christie, M. 2006. Towards a pedagogy of online learning. In: M. Christie, ed. Shifting perspectives in engineering education. Gothenburg: C-SELT.

Christie, M. 2007. UKeU and Sweden's Net University: a comparative study. In: The iCEER conference 3-6 December 2007, Victoria University, Melbourne, Australia.

Denscombe, M. 2006. The good research guide for small scale social research projects. Milton Keynes: OUP.

Dutton, W.H., Cheong, P., and Park, N. 2004. The social shaping of a virtual learning environment. Electronic Journal of e-learning, 2 (2), 1-12.

Garrote Jurado, R. 2006. The use of LMS in engineering education: a Swedish case study. In: M. Christie, ed. Shifting perspectives in engineering education. Gothenburg: C-SELT.

Garrote Jurado, R. and Pettersson, T. 2007. Lecturers' attitudes about the use of learning management systems in engineering education: a Swedish case study. Australasian Journal of Educational Technology, 23 (3), 327-349. 


\section{About the authors}

Michael Christie is a Professor of Higher Education at Chalmers University, Gothenburg, Sweden. He is the Director of a staff development unit that runs courses for Chalmers teachers and provides pedagogical support for the University. He is also in charge of a small research group that focuses on Engineering Education research.

Ramon Garrote Jurado is a lecturer at the University College of Borås. He lectures at the Engineering School in the area of computing science and has been actively researching the use of learning management systems in higher education. 